\title{
Intraoperative ventilation and hemodynamic change due to bladder perforation during transurethral resection of a bladder tumor - A case report -
}

Received April 25, 2017

Revised June 9, 2017

Accepted June 23, 2017

\section{Corresponding author}

Gunn Hee Kim, M.D., Ph.D.

Department of Anesthesiology and

Pain Medicine, National Medical

Center, 245, Eulji-ro, Jung-gu, Seoul

04564, Korea

Tel: 82-2-2260-7368

Fax: 82-2-2267-8685

E-mail: gunnhee@gmail.com

\section{Mijung Yun, Gunn Hee Kim, Seung Young Lee, Hana Cho, Byunguk Kim, Min Seok Koo, and Mi-Young Kwon}

Department of Anesthesiology and Pain Medicine, National Medical Center, Seoul, Korea

\begin{abstract}
Transurethral resection is the most efficacious and safest urologic procedure for the treatment of benign prostatic hypertrophy, prostate cancer, and bladder cancer. Complications of transurethral resection include hemorrhage, infection, transurethral resection syndrome, and bladder perforation. Early detection of bladder perforation is important because it can cause critical ventilation and hemodynamic changes. In this case, we detected bladder perforation as the cause of ventilation and hemodynamic change intraoperatively and treated it by immediate surgical repair.
\end{abstract}

Key Words: Bladder, Perforation, Transurethral resection.
Transurethral resection is a common, effective urologic procedure performed to resolve urinary tract obstruction in benign prostatic hypertrophy, prostate cancer, and bladder cancer. However, its complications include hemorrhage, infection, transurethral resection syndrome (TURS), bladder perforation, urinary tract obstruction, urinary incontinence, and sepsis $[1,2]$. While bladder perforation occurs in up to $58 \%$ of all cases, cases of bladder perforation that require surgical treatment are rare [3,4]. Risk for bladder perforation increases with advancing age, increasing tumor size, tumor position on the posterior wall of the bladder, and increasing number of previous treatments $[4,5]$. Bladder perforation rapidly escalates abdominal pressure, which in turn may alter vital signs and cause dyspnea. Bladder perforation that occurs intraoperatively is generally discovered by the operating urology surgeon or postoperatively by computed tomography (CT), cystogram, or cystoscopy [5]. Although many cases of bladder perforation during transurethral resection surgery have been reported, there have been few case reports describing the detection of bladder perforation during surgery $[6,7]$. Here, we report a case of bladder perforation that was diagnosed by the anesthesiologist while searching for the cause of ventilation and hemodynamic changes during transurethral resection under general anesthesia, along with a review of the relevant literature.

\section{CASE REPORT}

An 80-year-old male patient (weight $50 \mathrm{~kg}$, height $158 \mathrm{~cm}$ ) was scheduled to undergo transurethral resection of the bladder (TURB) for multiple masses, including a 3.8-cm mass in the left bladder wall, and prostatic hypertrophy. He had a history of hypertension with no other notable disease history, and had undergone three previous transurethral resection surgeries. Preoperative chest X-ray, pulmonary function test, electrocardiography, and echocardiography findings were normal. Two days before the operation, his hemoglobin and hematocrit counts were reduced to $8.6 \mathrm{~g} / \mathrm{dl}$ and $26.6 \%$,

This is an Open Access article distributed under the terms of the Creative Commons Attribution Non-Commercial License (http://creativecommons.org/licenses/by-nc/4.0) which permits unrestricted non-commercial use, distribution, and reproduction in any medium, provided the original work is properly cited. 
respectively, due to hematuria, but they were restored to normal levels on the day of surgery after 2 units of packed red blood cell transfusion (12.2 g/dl and 37.1\%, respectively). The patient's vital signs after arriving at the operating room were blood pressure 188/97 mmHg, heart rate (HR) 71 beats/min, respiratory rate (RR) 15 breaths/min, and peripheral arterial oxygen saturation 99\% (Table 1). After inducing anesthesia with lidocaine $40 \mathrm{mg}$, propofol $60 \mathrm{mg}$, and rocuronium 40 $\mathrm{mg}$, a 7.5-mm endotracheal tube was introduced and fixed at the 22-cm mark at the incisor level. Bilateral air entry was confirmed with auscultation, and anesthesia was maintained with $\mathrm{O}_{2} 1.1 \mathrm{~L} / \mathrm{min}$, medical air $1.9 \mathrm{~L} / \mathrm{min}$, sevoflurane 2 vol\%, and continuous infusion of remifentanil (1.0 to $3.0 \mathrm{ng} / \mathrm{ml})$. The ventilator was set to a tidal volume of $400 \mathrm{ml}$ and $\mathrm{RR}$ of 10 breaths/min, with peak inspiratory pressure (PIP) $19 \mathrm{cmH}_{2} \mathrm{O}$, plateau pressure $17 \mathrm{cmH}_{2} \mathrm{O}$, and $\mathrm{ETCO}_{2} 29 \mathrm{mmHg}$.

At about 30 minutes into TURB using a continuous-flow resectoscope, PIP slowly rose from $19 \mathrm{cmH}_{2} \mathrm{O}$ to $33 \mathrm{cmH}_{2} \mathrm{O}$ over about 10 minutes. At that time, breath sounds were clear. After confirming no problems with the position of the endotracheal tube or the circuits and connection, tracheal suction was performed because secretion was suspected. As PIP was still maintained at $32-34 \mathrm{cmH}_{2} \mathrm{O}$, bronchospasm was suspected; albuterol was sprayed 10 times, and Valsalva's maneuver was performed. Blood pressure continuously dropped from 160/90 to $95 / 70 \mathrm{mmHg}$, with HR maintained at $60-70$ beats $/ \mathrm{min}$. $\mathrm{ETCO}_{2}$ gradually dropped from 28 to 18 $\mathrm{mmHg}$. The plateau pressure of the airway also increased along with $\mathrm{PIP}$, from $17 \mathrm{cmH}_{2} \mathrm{O}$ to $30 \mathrm{cmH}_{2} \mathrm{O}$. While searching for the cause, we discovered that the abdomen was distended and very firm. Immediately after the discovery, we alerted the surgeon of the possibility of bladder perforation and recommended conversion to open surgery.

Abdominal X-ray taken during the process of open conversion showed ascites and emphysema in the properitoneal fat space and paranephric space. For continuous monitoring of arterial pressure and arterial blood gas analysis (ABGA), a $20 \mathrm{G}$ catheter was inserted into the left radial artery. Perioperative changes in arterial blood gas analysis are described in Table 2. Open surgery was started about 30 minutes after

Table 1. Perioperative Changes in Vital Signs

\begin{tabular}{lcccccccc}
\hline & $\begin{array}{c}\text { Before } \\
\text { induction }\end{array}$ & $\begin{array}{c}\text { During } \\
\text { TURB }\end{array}$ & $\begin{array}{c}\text { Initial PIP } \\
\text { elevation }\end{array}$ & $\begin{array}{c}\text { Upon stopping } \\
\text { TURB }\end{array}$ & $\begin{array}{c}\text { During open } \\
\text { surgery }\end{array}$ & $\begin{array}{c}\text { Recovery } \\
\text { room }\end{array}$ & $\begin{array}{c}\text { Patient } \\
\text { ward }\end{array}$ & $\begin{array}{c}\text { Day after } \\
\text { surgery }\end{array}$ \\
\hline SBP $(\mathrm{mmHg})$ & 188 & $110-150$ & 160 & 95 & $100-150$ & $140-160$ & 140 & $110-130$ \\
DBP $(\mathrm{mmHg})$ & 97 & $60-90$ & 90 & 70 & $50-80$ & $70-85$ & 80 & $60-75$ \\
HR (beats/min) & 71 & $50-75$ & 60 & 65 & $55-70$ & $60-75$ & 75 & $70-85$ \\
RR & 15 & 10 & 10 & 8 & $8-11$ & $10-20$ & 20 & 20 \\
BT $\left({ }^{\circ} \mathrm{C}\right)$ & 36.4 & $35.3-36$ & 35.3 & 35 & $34.3-34.5$ & 36.6 & 37 & $37-37.5$ \\
\hline
\end{tabular}

TURB: transurethral resection of the bladder, PIP: peak inspiratory pressure, SBP: systolic blood pressure, DBP: diastolic blood pressure, HR: heart rate, RR: respiratory rate, BT: body temperature.

Table 2. Perioperative Changes in Arterial Blood Gas Analysis

\begin{tabular}{|c|c|c|c|c|c|c|}
\hline & Pre-op & $\begin{array}{l}\text { Initial PIP elevation } \\
\qquad(09: 09)\end{array}$ & $\begin{array}{c}\text { During open } \\
\text { surgery } 1(10: 33)\end{array}$ & $\begin{array}{c}\text { During open } \\
\text { surgery } 2(11: 17)\end{array}$ & $\begin{array}{c}\text { During open } \\
\text { surgery } 3(12: 09)\end{array}$ & $\begin{array}{c}\text { Recovery } \\
\text { room }\end{array}$ \\
\hline $\mathrm{pH}$ & 7.420 & 7.463 & 7.246 & 7.295 & 7.325 & 7.298 \\
\hline $\mathrm{PaCO}_{2}(\mathrm{mmHg})$ & 32.4 & 28.0 & 42.0 & 38.2 & 35.0 & 34.2 \\
\hline $\mathrm{PaO}_{2}(\mathrm{mmHg})$ & 109 & 204 & 121 & 217 & 220 & 171 \\
\hline $\mathrm{Na}^{+}(\mathrm{mmol} / \mathrm{L})$ & 142 & 143 & 146 & 146 & 145 & 142 \\
\hline $\mathrm{K}^{+}(\mathrm{mmol} / \mathrm{L})$ & 3.6 & 2.7 & 2.7 & 2.8 & 2.7 & 3.4 \\
\hline $\mathrm{Hb}(\mathrm{g} / \mathrm{dl})$ & 12.2 & 12.6 & 10.9 & 9.9 & 9.2 & 11.4 \\
\hline Hct (\%) & 37.1 & 37 & 32 & 29 & 27 & 34 \\
\hline $\mathrm{FIO}_{2}$ & 0.21 & 0.5 & 0.5 & 0.6 & 0.6 & 0.4 \\
\hline
\end{tabular}

PIP: peak inspiratory pressure, $\mathrm{PaCO}_{2}$ : partial pressure of carbon dioxide, $\mathrm{PaO}_{2}$ : partial pressure of oxygen, Hb: hemoglobin, $\mathrm{Hct}$ : hematocrit, $\mathrm{FIO}_{2}$ : fraction of inspired oxygen. 
stopping TURB, and PIP dropped from 33 to $23 \mathrm{cmH}_{2} \mathrm{O}$ after the incision. A 1-cm rupture was found in the right lateral wall of the bladder, and irrigation fluid was leaking into the abdominal cavity. After repairing the rupture, two drains were mounted separately in the intraperitoneal and extraperitoneal space, and cystostomy was performed. A total of $18,000 \mathrm{ml}$ of normal saline was used for bladder irrigation, and 1,000 $\mathrm{ml}$ of ascetic fluid was drained. The total operation time was 4 hours and 10 minutes. After conclusion of surgery, the inhalation anesthesia was stopped, and neostigmine 2.0 $\mathrm{mg}$ and glycopyrrolate $0.4 \mathrm{mg}$ were intravenously injected to reverse the muscle blockade. The patient opened his eyes to an oral cue about 5 minutes after surgery, and spontaneous breathing was confirmed. Extubation was performed after confirming that muscle block was reversed sufficiently through a hand holding test.

The patient's recovery was uneventful. Postoperative hemoglobin was $10.5 \mathrm{~g} / \mathrm{dl}$ with hematocrit $32.8 \%$, blood sodium $137 \mathrm{mmol} / \mathrm{L}$, potassium $4.0 \mathrm{mmol} / \mathrm{L}$, and chloride $107 \mathrm{mmol} /$ L. The patient was discharged at postoperative day 14 without complications.

\section{DISCUSSION}

Bladder cancer is a malignant tumor that most commonly develops in genitourinary tract, and it develops superficially in $80 \%$ of cases [8]. Transurethral resection is the most efficacious and safest treatment for superficial tumors, but it is associated with various complications, including hemorrhage, urinary tract obstruction, and infection. In rare cases, it also leads to serious complications, such as bladder perforation and subsequent irrigation fluid leakage into the abdominal cavity, TURS, and sepsis [5,8].

The incidence of bladder perforation is suspected of being higher than reported [4]. However, bladder perforation caused by transurethral resection rarely requires surgical treatment. Risk factors for bladder perforation during transurethral resection include tumor size, age, prior bladder treatments (such as previous TURB, intravesical instillation, or radiotherapy), and location of the tumor (dome or diverticulum) [5]. In the present case, the size of the tumor was fairly large $(3.8 \mathrm{~cm})$, and the patient was elderly (80 years) and had undergone three prior TURB surgeries. In addition, the tumor was spread over the entire bladder, putting the patient at high risk group for bladder perforation that could require surgical treatment [4].

Bladder perforation is classified as extraperitoneal rupture and intraperitoneal rupture, and it is important to distinguish between the two because they require different treatments [9]. For cases involving only extraperitoneal rupture, conservative treatment, including bladder drainage, is performed, with the rare exception of severe cases involving large perforations. By contrast, for cases that also involve an intraperitoneal rupture, the standard treatment is to repair the rupture via an open surgery [5] because intraperitoneal ruptures are typically large in size and show persistent urine leakage, thereby increasing the risk of fatal peritonitis [9]. The present case fell into the latter type (mixture of extraperitoneal and intraperitoneal ruptures), and the rupture was repaired via open surgery as soon as it was suspected. The bladder was drained via a Foley catheter and cystostomy to prevent urine leakage, and peritonitis was prevented by mounting two drainage tubes into the intraperitoneal and extraperitoneal areas to drain the leaked irrigation fluid and urine.

In this case, rising PIP and plateau pressure were discovered as the first signs of rupture. The various causes of increased PIP can be broadly divided into two groups depending on the presence or absence of a concurrent rise in plateau pressure. Concurrent increase of PIP and plateau pressure may be attributable to reduced pulmonary compliance caused by increased tidal volume, pulmonary edema, Trendelenburg position, pleural effusion, endobronchial intubation, or tension pneumothorax or to reduced pulmonary compliance caused by increased abdominal pressure involving ascites, abdominal packing, or peritoneal gas insufflation. When only the PIP is increased, greater airway resistance caused by increased inspiratory gas flow rate, endotracheal tube bending, bronchospasm, secretions, foreign body aspiration, airway compression, or endotracheal tube cuff herniation may be the culprit [10]. In the present case, there were no signs of aspiration before or after induction, the bilateral airway entry was auscultated, and neither the tidal volume nor inspiratory gas flow rate were manipulated until PIP increased. In addition, we checked that the breathing circuit was not bent, and confirmed the tube location once again, considering the possibility of endobronchial intubation due to intraoperative alteration of tube position. Although clean breath sounds were auscultated, tracheal suction and 
albuterol were administered to rule out the possibility of secretion and bronchospasm. Then the physical examination was repeated, during which abdominal distention was discovered. Ultimately, ascites-induced increase of abdominal pressure was concluded to be the cause of increased PIP.

A perioperative increase of abdominal pressure may have various causes, including hemorrhage, edema, ileus, and abscess $[11,12]$. Elevated abdominal pressure not only disturbs the local blood flow within the abdominal cavity but also has detrimental effects on non-abdominal organs and systems. First, elevated abdominal pressure affects the cardiovascular system by increasing intrathoracic pressure [13], which in turn reduces cardiac output by considerably lowering venous return. Next, elevation of abdominal pressure adversely impacts the respiratory system, as it increases extrinsic compression of the lungs and expands the diaphragm against the lungs. This in turn causes reduced carbon dioxide release and arterial hypoxemia by increasing atelectasis, reducing capillary flow, and increasing dead space. While the tidal volume and minute volume drop, airway pressure significantly increases. Elevated abdominal pressure may also lead to acute renal failure, gastrointestinal mucosal damage, liver damage caused by reduced hepatic blood flow, and abdominal wall ischemia $[11,14]$. As shown in Table 1, blood pressure continuously dropped from the point of PIP elevation to open conversion, that is, during the period of obstructed venous return caused by elevated abdominal pressure. Moreover, as previously mentioned, PIP was elevated while the abdominal pressure remained high, during which time sufficient tidal volume and minute volume were not achieved. The third ABGA results shown in Table 2 indicated that partial pressure of carbon dioxide was elevated to $42 \mathrm{mmHg}$, while partial pressure of oxygen had fallen to $121 \mathrm{mmHg}$.

Bladder rupture caused by transurethral resection is generally intraoperatively discovered by the operating urology surgeon based on the observation of fat tissue, muscle, and bowel through the endoscopic monitor, the bladder failing to expand with the irrigation fluid, or a small volume of irrigation fluid being drained [3]. After surgery, it is discovered through CT, cystoscopy, or cystogram [5,15]. Early discovery is critical, as postoperative discovery of bladder rupture increases the risk of TURS or peritonitis due to the prolonged accumulation of irrigation fluid within the abdominal cavity. Thus, anesthesiologists must be fully aware of the patient characteristics associated with a high risk for serious bladder rupture that requires surgery. Further, in high-risk patients, anesthesiologists must also pay attention to monitoring of hemodynamic and respiratory changes and should not neglect physical examinations, especially abdominal distension, for the early detection of bladder rupture during TURB. In the present case, PIP elevation prompted a physical examination of the patient, which led to the discovery of abdominal distention. The authors report this case because physical examination, which is often neglected in operating rooms, enabled early diagnosis and administration of appropriate treatment, ultimately shortening the patient's recovery period and facilitating improvement without complications.

\section{REFERENCES}

1. Gravenstein D. Transurethral resection of the prostate (TURP) syndrome: a review of the pathophysiology and management. Anesth Analg 1997; 84: 438-46.

2. Kim HH, Kwak C, Seo SI, Chung H, Lee ES, Lee CW. The effects and complications of transurethral resection for benign prostatic hyperplasia: results of long-term follow-up. Korean J Urol 1996; 37: 268-80.

3. Balbay MD, Cimentepe E, Unsal A, Bayrak O, Koç A, Akbulut Z. The actual incidence of bladder perforation following transurethral bladder surgery. J Urol 2005; 174: 2260-2.

4. Golan S, Baniel J, Lask D, Livne PM, Yossepowitch O. Transurethral resection of bladder tumour complicated by perforation requiring open surgical repair - clinical characteristics and oncological outcomes. BJU Int 2011; 107: 1065-8.

5. Summerton DJ, Kitrey ND, Lumen N, Serafetinidis E, Djakovic N. EAU guidelines on iatrogenic trauma. Eur Urol 2012; 62: 628-39.

6. Lee MK, Lee YS. Sudden hypothermia after bladder perforation during transurethral bladder tumor resection: a case report. Anesth Pain Med 2010; 5: 173-6.

7. Kim SH, Son HJ, Kim JW, Kong YG, Hwang JH, Kim YK. Severe postoperative dyspnea caused by neglected massive intraperitoneal fluid collection during laser enucleation and morcellation of the prostate: a case report. Korean J Anesthesiol 2016; 69: 1858.

8. Collado A, Chéchile GE, Salvador J, Vicente J. Early complications of endoscopic treatment for superficial bladder tumors. J Urol 2000; 164: 1529-32.

9. Santucci RA, McAninch JW. Bladder injuries: evaluation and management. Braz J Urol 2000; 26: 408-14.

10. Butterworth JF, Mackey DC, Wasnick JD. Morgan \& Mikhail's 
Clinical Anesthesiology. 5th ed. New York, Lange. 2013, pp 7780.

11. Papavramidis TS, Marinis AD, Pliakos I, Kesisoglou I, Papavramidou N. Abdominal compartment syndrome - Intra-abdominal hypertension: Defining, diagnosing, and managing. J Emerg Trauma Shock 2011; 4: 279-91.

12. Malbrain ML, Cheatham ML, Kirkpatrick A, Sugrue M, Parr M, De Waele J, et al. Results from the international conference of experts on intra-abdominal hypertension and abdominal compartment syndrome. I. definitions. Intensive Care Med 2006; 32: 1722-32.
13. Bloomfield GL, Ridings PC, Blocher CR, Marmarou A, Sugerman HJ. A proposed relationship between increased intra-abdominal, intrathoracic, and intracranial pressure. Crit Care Med 1997; 25: 496-503.

14. Ridings PC, Bloomfield GL, Blocher CR, Sugerman HJ. Cardiopulmonary effects of raised intra-abdominal pressure before and after intravascular volume expansion. J Trauma 1995; 39: 1071-5.

15. Gomez RG, Ceballos L, Coburn M, Corriere JN Jr, Dixon CM, Lobel B, et al. Consensus statement on bladder injuries. BJU Int 2004; 94: 27-32. 